\title{
Assigning people to roles in software projects
}

\author{
Silvia T. Acuña ${ }^{1, *, \dagger}$ and Natalia Juristo ${ }^{2}$ \\ ${ }^{1}$ Departamento de Ingeniería Informática, Escuela Politécnica Superior, \\ Universidad Autónoma de Madrid, Ctra. de Colmenar Km 15, 28049 Madrid, Spain \\ ${ }^{2}$ Departamento de Ingeniería del Software, Facultad de Informática, Universidad Politécnica de Madrid, \\ Campus de Montegancedo s/n, 28660 Boadilla del Monte, Madrid, Spain
}

\begin{abstract}
SUMMARY
This paper is based on the premise that people's behavioural competencies or characteristics of professional conduct influence the effectiveness and efficiency with which they perform a predetermined role in the software process. We propose a capabilities-oriented process model that includes traditional elements of the software process (activities, products, techniques, people and roles) and the original element of this paper (capabilities). With the aim of adding behavioural competencies to the process model, we define the capability-person and capability-role relationships involved in software development. Additionally, we propose two procedures that are based on each of these relationships: a procedure that can be used to determine the capabilities of the members of a development team; and a procedure that can be used to assign people to perform roles depending on their capabilities and the capabilities demanded by the roles. Finally, the person-capabilities-role relationship has been empirically validated. The results yielded by this experiment confirm the hypothesis that assigning people to roles according to their capabilities and the capabilities demanded by the role improves software development. Copyright $(c) 2004$ John Wiley \& Sons, Ltd.
\end{abstract}

KEY WORDS: process modelling; software process; people; development team; person-role fit; capabilities

\section{INTRODUCTION}

As the ultimate objective of modelling the software process is to know, control and manage the process activities, organizational environments need to be considered. Particularly, the relationships between the modelled software processes and the organizational environments need to be analysed. People are the least formalized factor in today's software process models. However, their importance is evident: people behave non-deterministically and subjectively, having a decisive impact on the results of software production, which is a primarily intellectual and social activity [1].

Failure to specify the people factor in the process represents the risk of developers performing activities that are beyond their capabilities. Existing process models do not formalize the skills

*Correspondence to: Silvia T. Acuña, Departamento de Ingeniería Informática, Escuela Politécnica Superior, Universidad Autónoma de Madrid, Ctra. de Colmenar Km 15, 28049 Madrid, Spain.

†E-mail: silvia.acuna@ii.uam.es 
and capabilities of each member (managers, developers, support personnel, practitioners, experts, customers and users) to assure that the project team is effective and efficient $[2,3]$. This makes it difficult to manage the knowledgeable and creative people who perform the development process activities, as there are no defined procedures for assigning people to roles according to their capabilities and the capabilities demanded by the role.

These problems are indicative of the need for software process models that cover both the technical and human parts of the process. In this context, we have developed a Capabilities-Oriented Software Process Model [4]. This model includes the formalization of the capabilities or behavioural competencies of the people who perform the development activities. The hypothesis we aim to test in this research is that the inclusion of two elements that are not usually present (the capabilities of people and the capabilities of roles), apart from the standard four elements of software process models (activities, products, people, roles), improves the software development process.

First, we define the capability-person and capability-role relationships. Second, we describe the two procedures in which these relationships are involved: Evaluation of People's Capabilities Procedure and Assignation of People to Roles Procedure, respectively. The Evaluation of People's Capabilities Procedure can be used to determine the capabilities of the people involved in the software process. The Assignation of People to Roles Procedure can be used to assign people to roles according to the development project capabilities. Additionally, we present the empirical validation of the proposed solution.

Note that the logic of core competencies, the theory upon which our solution is based, is not a new approach in human resources management. This logic is now practised in many organizations for different purposes, such as personnel selection and recruitment, job analysis, organizational learning or financial evaluation [5,6]. However, this logic has not yet been routinely applied in the context of the software process. Although there are ad hoc solutions, such as the PARYS system [7] for the Automobile Association and the Fraunhofer-IESE's QUALISEM system [8], there does not appear to have been any continuation, even though the issue is interesting and important. The process model proposed here should be considered as a contribution to developing this logic of core competencies for the software process. Unlike the People-CMM [9], our model uses the Assessment Center Method [10] to deal with the more subjective part of the software process-people. There have been other attempts to relate social and technical systems [11-13], but the integration of peopleware into the software development process is still very poor [14,15]. Our working premise is that people's behavioural competencies or characteristics of professional conduct influence the effectiveness and efficiency with which they perform a predetermined role in the software process.

The remainder of the paper is structured as follows. Section 2 discusses related work. Section 3 gives an overview of the proposed solution. Section 4 classifies the capabilities involved in the software process. Sections 5 and 6 formalize the theoretical contributions of this paper, that is, the definition of the capability-person and capability-role relationships. Sections 7 and 8 present the evaluation of people's capabilities procedure and assignation of people to roles procedure, respectively. Section 9 describes the experimentation. Finally, Section 10 discusses the conclusions.

\section{RELATED WORK}

The need for highly trained personnel for developing software has been a subject of discussion since the 1980s [15-17]. In the field of sociocultural systems, there are two methodologies focused on 
organizational design and modelling: the Soft Systems Methodology [18] and Methodology to Define Weltanschauungen [19]. In the area of software process evaluation, there is now (a) the PeopleCMM [9], focused on the human resource factor; (b) the Personal Software Process [20], focused on individual performance; and (c) the Team Software Process [21], which deals with software process improvement at the team level. In the area of software process modelling, however, the inclusion of human resources and the interaction in which they participate is not at all conceptualized or formalized [22-24].

We have analysed the foremost models existing in the literature that define the person element of the process: Soft Systems Methodology [18], Methodology to Define Weltanschauungen [19], Systems Dynamics [25], People-CMM [9], SOCCA [22], ALF [26] and the Unified Software Development Process [27]. The following criteria were used for the analysis: (a) process elements covered by the work analysed; (b) process environments; (c) the presence of a modelling procedure, that is, whether or not the model provides a set of stages for outputting the modelling components; (d) if such a procedure exists, whether the procedure proposed by each model covers all or only part of the elements and essential characteristics of the process; and (e) in how much detail the stages are defined. We do this to check whether the models studied contemplate and represent the three environments (organizational, cultural and technological) that are important for the management of both the activities and the members of a project team.

The analysed organization-oriented models are general and qualitative prescriptions, which focus on the study of agents and roles. The Soft Systems Methodology focuses on the social system of the organization, neglecting the technical development activities and aspects of the organizational processes. The Methodology to Define Weltanschauungen models the organizational roles and role and human agent capabilities, by means, however, of an informal representation. Both models only contemplate the organizational processes and do not cover the software processes. Additionally, although they provide a developed modelling procedure, this procedure is neither complete nor fully defined, as it does not address the integration of the organizational, cultural and technological environments and only considers the former two.

The software process models considered focus on examining the process agents, attaching less importance to other process elements like roles, for example, which are not formally defined, and human and role capabilities, which are not explicitly modelled. The main drawback of all these models is that they do not consider the cultural environment of the software process and its integration with the organizational and technological environments. The People-CMM is the only one that models the capabilities of the human resources belonging to the organization and their associated roles in the software process, but the capabilities of the agents are represented informally and no modelling procedure has been developed for their inclusion in the software process. The strength of the model proposed in this paper lies, as mentioned earlier, in its use of intrinsically subjective methods (Assessment Center Method) to deal with people, the most subjective part of the software process. The People-CMM, by contrast, tried to come up with simplistic, objective techniques that are not best suited to this problem. The Systems Dynamics-based model offers a quantitative and deterministic description of the organization's human resources from the viewpoint of the human resource recruitment, training, inclusion and transfer experience level and not as regards the logic of competencies of the human resources and roles. The models that account for people do not provide a defined set of stages or activities for performing the modelling process. Only SOCCA and the Unified Software Development Process provide a defined procedure as an aid for modelling, but they do not 
address all the model components, for example, the cultural characteristics of the people involved in the software process. These two models, along with ALF, do not consider role capabilities and the assignation of people to roles according to their capabilities. None of the models studied provides a fully defined and complete modelling procedure; the capability process element is not present or automated.

From this analysis, it follows that the reviewed models are lacking in

- a detailed definition of the capabilities of the people and of the roles and their interactions in the software process;

- a well-defined, complete and detailed procedure to guide in integrating both the technical and human parts of the process in the model.

\section{OVERVIEW OF THE PROPOSED SOLUTION}

Figure 1 shows the overview of the proposed solution. Firstly, we have defined a process model that we have called the Capabilities-Oriented Software Process Model. For a full description of this model, see [4]. The process model has been formalized in UML and implemented as a tool that is available at http://www.ls.fi.upm.es/spt/. This tool is being used in two organizations in Argentina and one in Spain as an exploratory system for distributing roles in medium-sized software development projects. In this paper, however, we will focus on people and their capabilities.

Secondly, we have formalized the capability-role and capability-person relationships (highlighted in grey in Figure 1). These formalizations are based on technical and conceptual tools used in the sciences of organizational behaviour and integrated management of human resources [5,10], which are founded on well-established principles of psychology and, particularly, labour psychology.

Finally, the capability-person relationship is involved in the Evaluation of People's Capabilities Procedure and the capability-role relationship in the Assignation of People to Roles Procedure (Figure 1). Therefore, for each proposed subprocess, a procedure is defined to assist in building models of the people involved in the software processes and the assignation of roles in software projects.

In the following, we will define the capability-person and the capability-role relationships and, finally, we will describe the evaluation of people's capabilities and the assignation of people to roles procedures.

\section{CAPABILITIES FOR THE SOFTWARE PROCESS}

The role, person and capability elements of software process are defined as follows.

- Role defines a set of responsibilities and capabilities needed to perform the activities of each subprocess. For each role, a profile is developed, that is, its required capabilities are determined.

- Person defines the human actors who have the necessary capabilities to perform a given role. A profile is developed for each person involved in the software process.

- Capability defines the skill or attribute of the personal behaviour of a person that can be considered as a behavioural characteristic and according to which activity-oriented behaviour can be logically and reliably classed. This element is an original contribution of this research and is key to the definition of the above-mentioned procedures. 


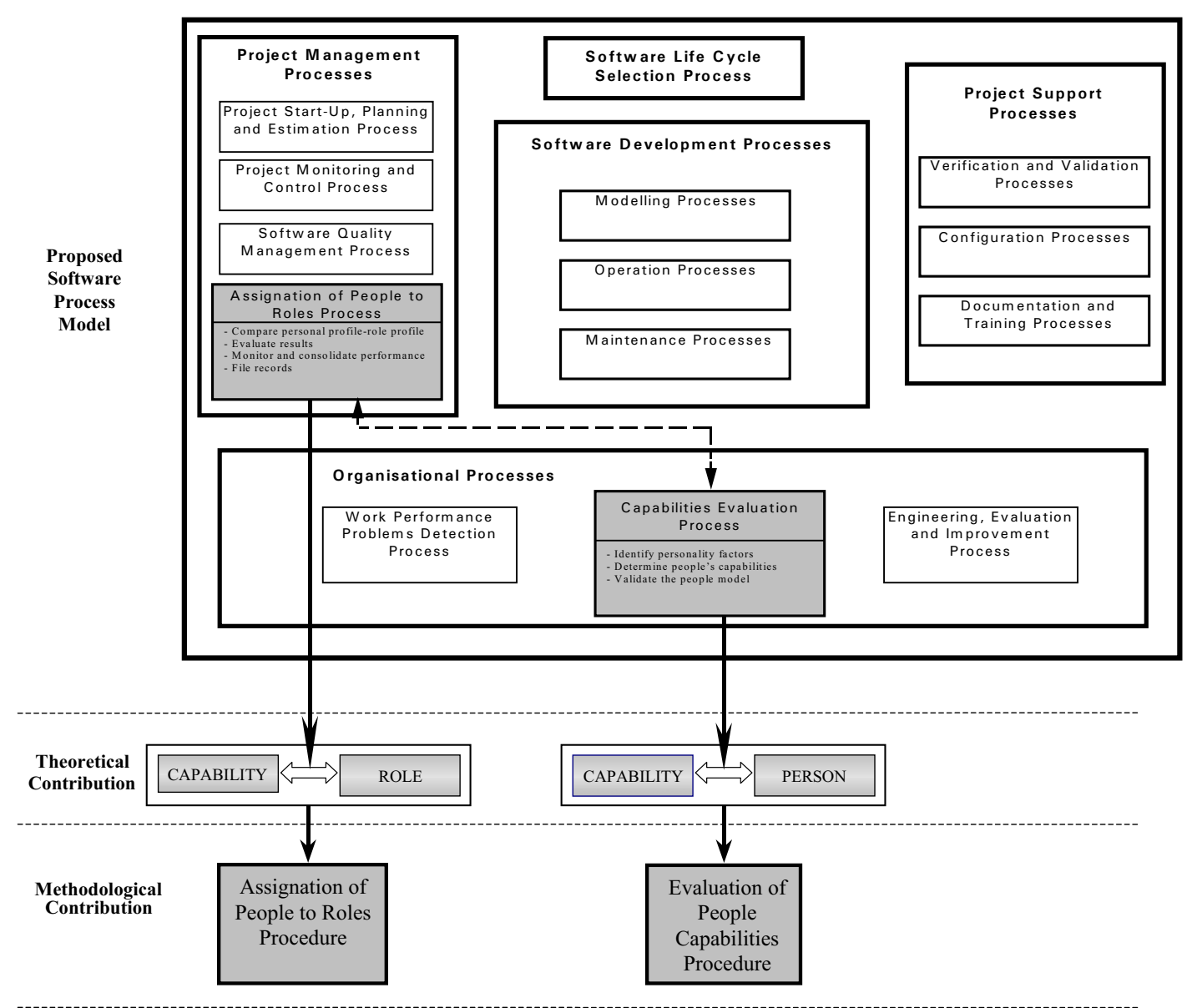

Figure 1. Overview of the proposed solution.

We have studied and analysed the lists of capabilities or behavioural competencies of people that are used to select job candidates [5,28], validated within the framework of the Assessment Center Method [10]. The use of this method brings with it a series of benefits that have been repeatedly observed by researchers [28], such as (a) better predictions of the behaviour of the person in real job performance; (b) participation of managers in the evaluation process; (c) lower level of inference by the evaluator; and (d) more powerful identification of weaknesses in specific behaviour-operative skills, which makes it possible to design specific training processes. This method, which takes a functionalist, behavioural and situational approach, is a consolidated line within labour psychology. Since it appeared in the early 1970s, this method has been used routinely for people management in other fields of 
Table I. Definition of capabilities.

\begin{tabular}{|c|c|}
\hline Capability & Description \\
\hline Analysis & $\begin{array}{l}\text { Identify organizational and/or software problems, recognize significant } \\
\text { information, locate and coordinate important data, diagnose possible causes. }\end{array}$ \\
\hline Decision making & $\begin{array}{l}\text { Active decision making, selecting one problem-solving alternative from several. } \\
\text { Commitment to specific opinions, acting in consequence and accepting } \\
\text { responsibility for such actions. }\end{array}$ \\
\hline Independence & $\begin{array}{l}\text { Act on the basis of one's own convictions rather than trying to meet other } \\
\text { people's expectations. Uphold the same opinion as far as possible. }\end{array}$ \\
\hline Innovation/creativity & $\begin{array}{l}\text { Discover new solutions to work-related problems and alternatives to classical } \\
\text { solutions, problem-solving methods and approaches. }\end{array}$ \\
\hline Judgement & $\begin{array}{l}\text { Consider factors and possible courses of action in the light of significant criteria } \\
\text { and reach realistic judgements. }\end{array}$ \\
\hline Tenacity & $\begin{array}{l}\text { Stick to the viewpoint or plan of action until the pursued objective is achieved } \\
\text { or until it is no longer reasonable to insist. Keep up the same behaviour as far as } \\
\text { possible. }\end{array}$ \\
\hline Stress tolerance & $\begin{array}{l}\text { Act effectively albeit it under time pressure and in the face of disagreement, } \\
\text { opposition and adversity. }\end{array}$ \\
\hline Self-organization & $\begin{array}{l}\text { Effectively organize one's own agenda of activities, establishing the necessary } \\
\text { priorities and using one's own time as efficiently as possible. }\end{array}$ \\
\hline Risk management & $\begin{array}{l}\text { Describe and estimate the likelihood and impact of the software process, project } \\
\text { or product development risk as a basis upon which to develop the steps to manage } \\
\text { each risk. }\end{array}$ \\
\hline Environmental knowledge & $\begin{array}{l}\text { Be aware of the specific conditions of the working environment. Master } \\
\text { up-to-date information on the computerized systems and software engineering } \\
\text { and knowledge engineering environment. }\end{array}$ \\
\hline Discipline & $\begin{array}{l}\text { Follow organizational policies and procedures. Look for information on changes } \\
\text { in the competent authority. }\end{array}$ \\
\hline Environmental orientation & $\begin{array}{l}\text { Be aware of social, economic and political developments and other } \\
\text { environmental factors that can affect the work or the organization. That is, keep } \\
\text { up with the broad activity development trends that affect one's own job or } \\
\text { business globally in terms of major progress or general aspects. }\end{array}$ \\
\hline Customer service & $\begin{array}{l}\text { Perceive and be able to reasonably satisfy the needs and demands of the customer } \\
\text { with respect to the information system according to budgetary constraints and } \\
\text { organizational resources. }\end{array}$ \\
\hline Negotiating skills & $\begin{array}{l}\text { Identify one's own and other people's positions in a negotiation, exchanging } \\
\text { concessions and reaching satisfactory agreements on the basis of a 'win/win' } \\
\text { philosophy. }\end{array}$ \\
\hline Empathy & $\begin{array}{l}\text { Be aware of and be able to satisfy the present or future needs or demands of } \\
\text { a set of potential clients (the abstract client) of the software user or developer } \\
\text { organization from any level of the organization. For example, the organizational } \\
\text { domain analyst is user-oriented, the systems analyst should have empathy with } \\
\text { the knowledge analyst and the requirements specifier, the requirements specifier } \\
\text { with the designer, the designer with the implementer, etc. }\end{array}$ \\
\hline Sociability & $\begin{array}{l}\text { Effortlessly interact with other people. Easily make contacts and engage in social } \\
\text { activities. }\end{array}$ \\
\hline Teamwork/cooperation & $\begin{array}{l}\text { Participate actively in achieving a common goal, even when cooperation leads to } \\
\text { a goal that is not directly related to one's own interests. }\end{array}$ \\
\hline
\end{tabular}


Table I. Continued.

\begin{tabular}{ll}
\hline Capability & \multicolumn{1}{c}{ Description } \\
\hline Co-worker evaluation & $\begin{array}{l}\text { Be skilful and discerning with regard to the evaluation of the professional } \\
\text { aspects of co-worker performance, using the interview, performance assessment, } \\
\text { potential development techniques, etc., satisfactorily. } \\
\text { Guide and direct a team and establish and maintain the team spirit needed to } \\
\text { achieve the team's objectives. } \\
\text { Planning and organization } \\
\text { Effectively determine goals and priorities, stipulating the actions, deadlines and } \\
\text { resources required to achieve them. }\end{array}$ \\
\hline
\end{tabular}

production and organization. The better management of human competencies is now becoming a source of improvement of industrial performance for many companies, be they goods production, service or administrative organizations [29]. We select and adapt the capabilities pertinent to software development. We consider 20 general capabilities to be critical in software development. To establish this list of capabilities, we have considered the desired job performance results for individual situations, one-to-one interpersonal situations and group interpersonal situations. Beforehand, we held structured interviews with managers and practitioners who actually do the job to establish these capabilities. We then held nine meetings with experts on each set of subprocesses of the proposed process (Figure 1) and the labour psychologist Marta Aparicio from the School of Psychology at Madrid's Complutense University to refine and validate the defined list of capabilities. These capabilities cover both functional theoretical elements and cognitive elements. These capabilities are general behavioural competencies, which refer exclusively to a person's general behavioural characteristics or skills used during a software development project. The definitions of the capabilities are shown in Table I. We have divided these capabilities into four categories: intrapersonal skills, organizational skills, interpersonal skills and management skills. This classification is based on the levels of skills acquisition during staff development. The definitions of the four categories and their associated capabilities are shown in Table II.

The capabilities shown in Table II characterize the capability-person relationship. The definition of this relationship is used in the Evaluation of People's Capabilities Procedure, which involves determining the capabilities of a person to then assign a role to this person in the process. The Capabilities Evaluation Process is closely related to the Assignation of People to Roles Process, basically through the capabilities element. Capabilities are the integrating element between the profile of each person and the profile of each role. It is impossible to predict how people will behave and assign them to a role with any chance of success, even if their capabilities are known, unless the behavioural competencies demanded by the role are known. Consequently, we have defined the capability-role relationship, and software project managers are given a procedure, which eases the task of assigning people to roles to create the project team structure.

Therefore, capabilities are used in both the Evaluation of People's Capabilities Procedure and the Assignation of People to Roles Procedure and are determined for each person involved in software development. Also, they are assigned to each of the roles of the proposed process model. 


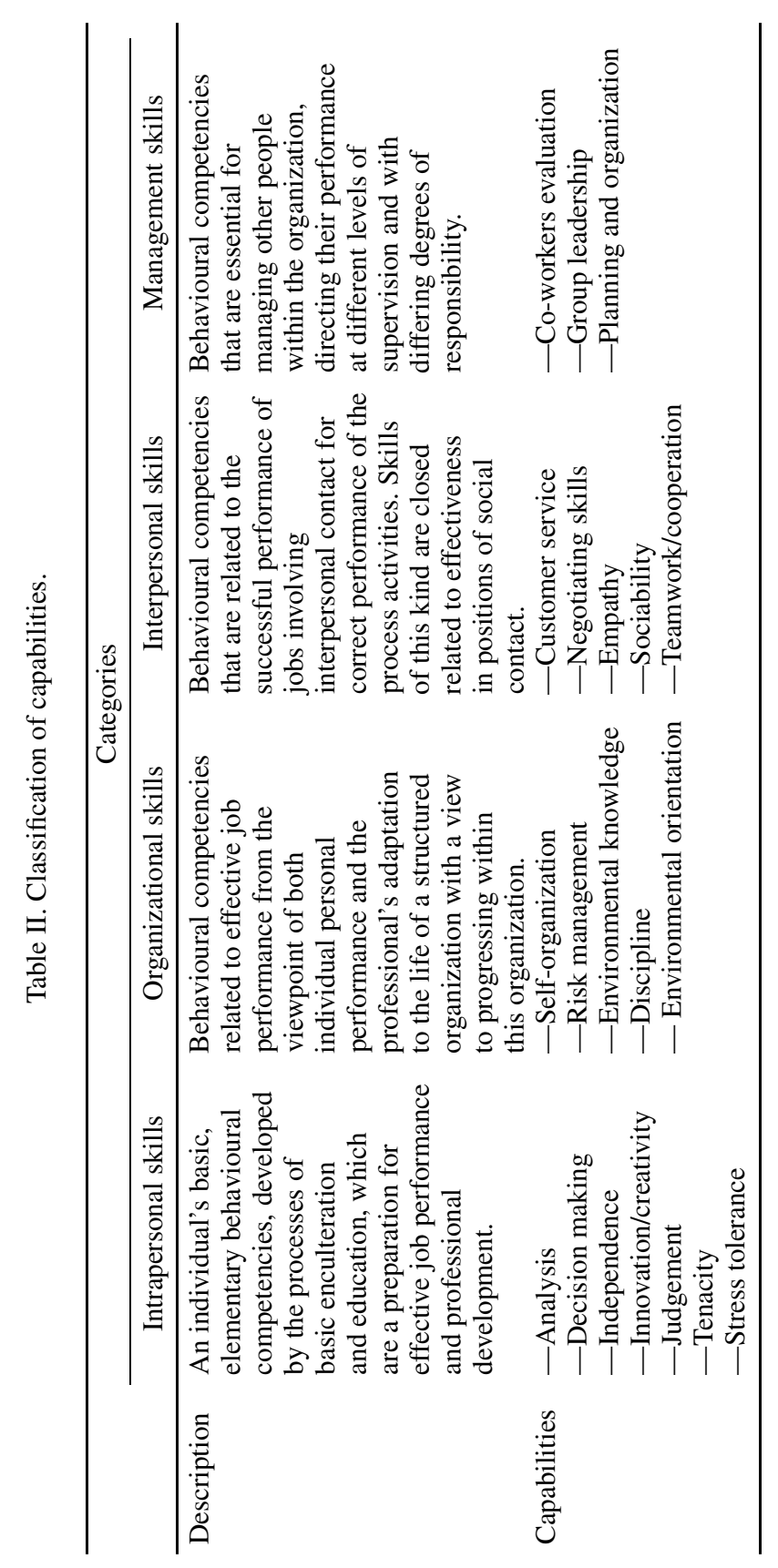




\section{CAPABILITY-PERSON RELATIONSHIP}

To determine what personality or behavioural factors indicative of personality are associated with the people involved in the software development process, we propose a table of correspondence (Table III) between each one of the 20 capabilities of Table II and the personality factors of a psychometric test. In particular, we use the projective 16 PF-5 personality test, described by Russell and Karol [30]. This test has been selected as it is one of the most commonly used instruments today and because it is adapted and correlated with given personality tests for psychologists. The 16 PF-5 test measures 16 primary personality traits identified by Cattell et al. [31], such as warmth, reasoning ability and emotional stability, among others, which describe primary human behaviours, and five global personality dimensions, like extroversion, anxiety, tough-mindedness, independence and self-control. Each of these factors has a low pole (represented by the sign '-') and a high pole (represented by the sign ' + '). For example, emotional stability - describes a reactive and emotionally insecure person and emotionally stability + , an emotionally stable, adapted and mature person. This psychometric test can be used to determine behaviours indicative of the capabilities of a person by means of factorial analysis of the set of global personality descriptors.

We have built the table of correspondence (Table III) between the personality factors of the 16 PF-5 test and people's capabilities in order to evaluate personality structure by means of suitably validated and correlated factors. Additionally, Table III provides the project leader, who conducts this evaluation together with the labour psychologist before assigning people to roles, with a friendly interface with the evaluation of people's capabilities procedure through the four categories of capabilities defined in this paper. For the Analysis column, for example, the person's behaviour should be indicative of Reasoning+, that is, the person should be a good thinker, be sharp and a quick learner, and of Abstraction-, that is, a practical-minded, realistic person with his or her feet firmly on the ground. Having identified the primary traits and global dimensions of the individual's personality by means of the 16 PF-5 test, this table of correspondence is used in the Evaluation of People's Capabilities Procedure to integrate these factors and determine the capabilities pertinent to software development, as described in Section 7.

Two tasks were performed to define this correspondence: (a) a two-way analysis of the personality requirements of each capability, as well as the behavioural aspects of each personality factor; and (b) an assessment with the participation of labour psychologists from the Complutense University of Madrid and TEA, Spain.

\section{CAPABILITY-ROLE RELATIONSHIP}

We propose to assign capabilities to roles as shown in Table IV. For each role of the software process we have defined the capabilities required to successfully achieve the associated activities. The proposed capabilities are compulsory for each role. Nevertheless, the person could have other desirable capabilities. Each of these capabilities is weighted at two levels: high $(\mathrm{H})$ and medium $(\mathrm{M})$. The weighting indicates that a high or medium level of the capability is required.

This table was built by analysing the behavioural competencies required to effectively perform each role. For this purpose, we carried out a process of reflection that involved many tasks of analysis: (a) analysis of the activities performed by each role; (b) analysis of the critical situations for successful 
Table III. Correspondence between the personality factors of the 16 PF-5 test and the proposed capabilities.

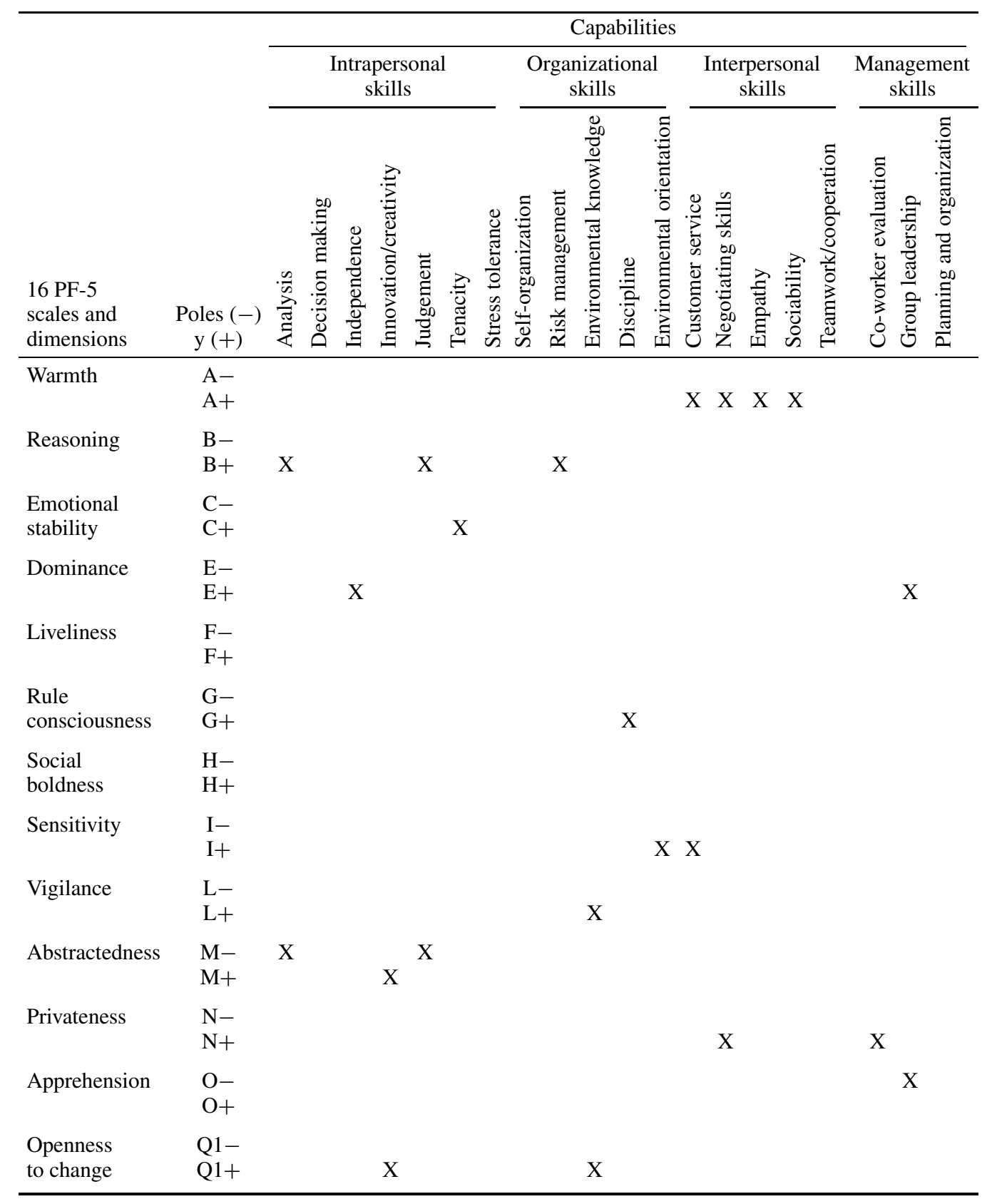


Table III. Continued.

\begin{tabular}{|c|c|c|c|c|c|c|c|c|c|c|c|c|c|c|c|c|c|c|c|c|}
\hline \multirow[b]{3}{*}{$\begin{array}{l}16 \mathrm{PF}-5 \\
\text { scales and } \\
\text { dimensions }\end{array}$} & \multirow[b]{3}{*}{$\begin{array}{c}\text { Poles }(-) \\
\mathrm{y}(+)\end{array}$} & \multicolumn{19}{|c|}{ Capabilities } \\
\hline & & \multicolumn{7}{|c|}{$\begin{array}{l}\text { Intrapersonal } \\
\text { skills }\end{array}$} & \multicolumn{5}{|c|}{$\begin{array}{c}\text { Organizational } \\
\text { skills }\end{array}$} & \multicolumn{4}{|c|}{$\begin{array}{l}\text { Interpersonal } \\
\text { skills }\end{array}$} & \multicolumn{3}{|c|}{$\begin{array}{l}\text { Management } \\
\text { skills }\end{array}$} \\
\hline & & $\frac{\sqrt[n]{5}}{\stackrel{2}{\vdots}}$ & 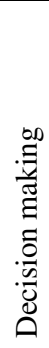 & 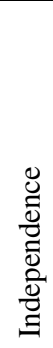 & 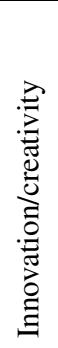 & 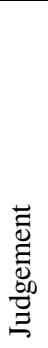 & 胥 & 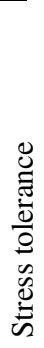 & 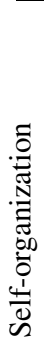 & 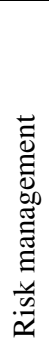 & 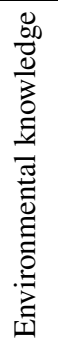 & 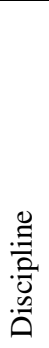 & 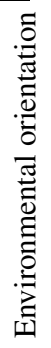 & 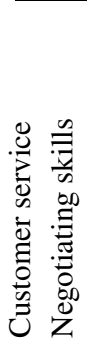 & 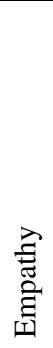 & 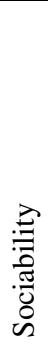 & 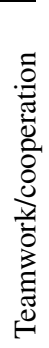 & 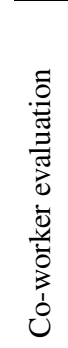 & 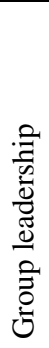 & 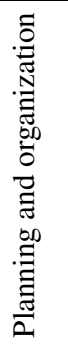 \\
\hline Self-reliance & $\begin{array}{l}\mathrm{Q} 2- \\
\mathrm{Q} 2+\end{array}$ & & & & & & & & & & & & & & & & $\mathrm{X}$ & & $\mathrm{X}$ & \\
\hline Perfectionism & $\begin{array}{l}\mathrm{Q} 3- \\
\mathrm{Q} 3+\end{array}$ & & & & & & $X$ & & $\mathrm{X}$ & & & & & & & & & & & $\mathrm{X}$ \\
\hline Tension & $\begin{array}{l}\mathrm{Q} 4- \\
\mathrm{Q} 4+\end{array}$ & & & & & & & $X$ & & & & & & & & & & & & \\
\hline Extroversion & $\begin{array}{l}\mathrm{EX}- \\
\mathrm{EX}+\end{array}$ & & & & & & & & & & & & & & & & & & & \\
\hline Anxiety & $\begin{array}{l}\text { ANX- } \\
\text { ANX+ }\end{array}$ & & & & & & & $X$ & & & & & & & & & & & & \\
\hline Tough-mindedness & $\begin{array}{l}\mathrm{TM}- \\
\mathrm{TM}+\end{array}$ & & $\mathrm{X}$ & & & & & & & & & & & & & & & & & \\
\hline Independence & $\begin{array}{l}\mathrm{IN}- \\
\mathrm{IN}+\end{array}$ & & & $\mathrm{X}$ & & & & & & & & & & & & & & & & \\
\hline Self-control & $\begin{array}{l}\mathrm{SC}- \\
\mathrm{SC}+\end{array}$ & & & & & & & & & & & & & & & & & & & \\
\hline
\end{tabular}

performance of each role, classified according to the four categories of capabilities described above, thus considering individual, organizational, group or management situations; and (c) analysis of the 20 proposed behavioural competencies, determining the competencies that are required to achieve a positive result in each of the critical situations. We should bear in mind, at all times, that these are critical situations where the desired outcome will not or is unlikely to be achieved unless they are properly resolved. Note, also, that required behavioural competencies refer to capabilities that are absolutely essential (and not merely desirable or just important). These are behavioural competencies that the person who performs the role must have. A person without these capabilities will be unable to entirely and satisfactorily deal with the critical situation, and the objective of the respective subprocess 
Table IV. Capabilities by model role.

\begin{tabular}{|c|c|c|c|c|c|c|c|c|c|c|c|c|c|c|c|c|c|c|c|}
\hline \multirow[b]{3}{*}{ Roles } & \multicolumn{19}{|c|}{ Capabilities } \\
\hline & \multicolumn{7}{|c|}{$\begin{array}{l}\text { Intrapersonal } \\
\text { skills }\end{array}$} & \multicolumn{5}{|c|}{$\begin{array}{c}\text { Organizational } \\
\text { skills }\end{array}$} & \multicolumn{5}{|c|}{$\begin{array}{l}\text { Interpersonal } \\
\text { skills }\end{array}$} & \multicolumn{2}{|c|}{$\begin{array}{l}\text { Management } \\
\text { skills }\end{array}$} \\
\hline & $\frac{\frac{n}{\infty}}{\frac{\pi}{\pi}}$ & 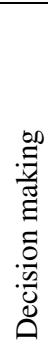 & 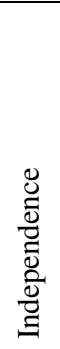 & 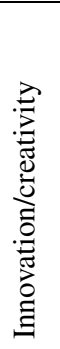 & 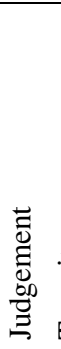 & 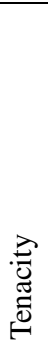 & 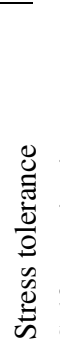 & 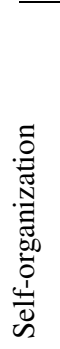 & 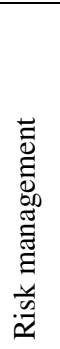 & 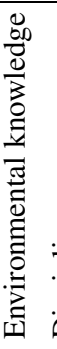 & 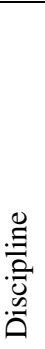 & 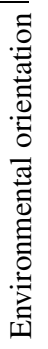 & 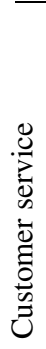 & 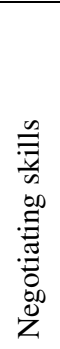 & 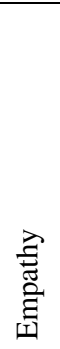 & 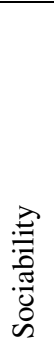 & 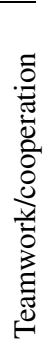 & 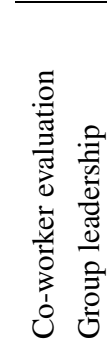 & 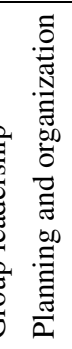 \\
\hline SLCM selector & $\mathrm{H}$ & $\mathrm{H}$ & $\mathrm{M}$ & $M$ & & $\mathrm{M}$ & $\mathrm{M}$ & & & $\mathrm{M}$ & $\bar{M}$ & M & & & $\mathrm{M}$ & & $\bar{M}$ & & \\
\hline Planner & $\mathrm{H}$ & $\mathrm{H}$ & $\mathrm{M}$ & M & $\mathrm{H}$ & & $\mathrm{H}$ & M & $\mathrm{H}$ & & & M & & $\mathrm{H}$ & $\mathrm{M}$ & & $\mathrm{H}$ & $\mathrm{MH}$ & $\mathrm{H} \mathrm{H}$ \\
\hline Controller & $\mathrm{H}$ & $\mathrm{H}$ & $\mathrm{M}$ & $\mathrm{M}$ & $\mathrm{H}$ & & $\mathrm{H}$ & $\mathrm{M}$ & $\mathrm{H}$ & & & M & & $\mathrm{H}$ & M & & $\mathrm{H}$ & M H & $\mathrm{H}$ \\
\hline Quality engineer & $\mathrm{H}$ & $\mathrm{H}$ & $\mathrm{M}$ & $\mathrm{M}$ & & & M & $\mathrm{M}$ & & & & $\mathrm{M}$ & & & $\mathrm{M}$ & & $\mathrm{H}$ & $\mathrm{MH}$ & $\mathrm{H} \mathrm{H}$ \\
\hline Role assigner & $\mathrm{H}$ & $\mathrm{H}$ & $\mathrm{M}$ & M & & & M & M & & & & M & & & M & & $\mathrm{H}$ & M H & $\mathrm{H} \mathrm{H}$ \\
\hline Organizational domain analyst & $\mathrm{H}$ & M & $\mathrm{M}$ & $\mathrm{H}$ & M & & M & & & $\mathrm{H}$ & & & & M & $\mathrm{M}$ & M & $\mathrm{H}$ & & \\
\hline Systems analyst & $\mathrm{H}$ & & & & $\mathrm{H}$ & & M & & & & & M & $\mathrm{H}$ & & M & M & $\mathrm{H}$ & & \\
\hline Knowledge analyst & $\mathrm{H}$ & & & & $\mathrm{H}$ & & M & & & & & M & $\mathrm{H}$ & & M & M & $\mathrm{H}$ & & \\
\hline Requirements specifier & $\mathrm{H}$ & & & & $\mathrm{H}$ & & M & & & & & M & $\mathrm{H}$ & & M & M & $\mathrm{H}$ & & \\
\hline Designer & $\mathrm{H}$ & $\mathrm{H}$ & $\mathrm{M}$ & & & $\mathrm{M}$ & M & $\mathrm{H}$ & & & M & M & & & M & & M & & \\
\hline Implementer & $\mathrm{H}$ & $\mathrm{H}$ & M & & & M & M & $\mathrm{H}$ & & & M & M & & & M & & M & & \\
\hline Installer & & & & & & $\mathrm{H}$ & $\mathrm{H}$ & $\mathrm{H}$ & & & M & M & $\mathrm{H}$ & & $\mathrm{H}$ & & M & & \\
\hline System operator & & & & & & $\mathrm{H}$ & $\mathrm{H}$ & $\mathrm{H}$ & & & M & M & $\mathrm{H}$ & & $\mathrm{H}$ & & M & & \\
\hline Maintainer & & & & & & $\mathrm{H}$ & $\mathrm{H}$ & $\mathrm{H}$ & & & M & M & $\mathrm{H}$ & & $\mathrm{H}$ & & M & & \\
\hline Retirement manager & & & & & & $\mathrm{H}$ & $\mathrm{H}$ & $\mathrm{H}$ & & & M & $\mathrm{M}$ & $\mathrm{H}$ & & $\mathrm{H}$ & & $\mathrm{M}$ & & \\
\hline Validator & & & $\mathrm{M}$ & & M & & $\mathrm{M}$ & $\mathrm{H}$ & & & $\mathrm{H}$ & M & & & M & & $\mathrm{H}$ & & \\
\hline Configuration manager & & & M & & M & & M & $\mathrm{H}$ & & & $\mathrm{H}$ & M & & & M & & $\mathrm{H}$ & & \\
\hline Documentalist & & & & & & & $\mathrm{M}$ & & & & M & $\mathrm{H}$ & & & $\mathrm{H}$ & & $\mathrm{H}$ & & \\
\hline Trainer & & & & & & & M & & & & M & $\mathrm{H}$ & & & $\mathrm{H}$ & & $\mathrm{H}$ & & \\
\hline Team manager & $\mathrm{H}$ & M & & M & & & M & & & M & & M & M & M & $\mathrm{H}$ & $\mathrm{H}$ & $\mathrm{H}$ & $\mathrm{H} \quad \mathrm{H}$ & $\mathrm{H} \mathrm{H}$ \\
\hline
\end{tabular}

will not be achieved. The result was reflected in tables similar to Table IV for critical situation and role. Finally, the list of behavioural competencies was systematically and fully reviewed in participatory sessions, indicating which capabilities are necessary for successfully resolving each of the critical situations and the relevance or importance (high or medium) of each one. People performing the role under analysis, people performing roles that supply input products to this role and people consuming the products generated by the role in question were involved in these participatory sessions, alongside a labour psychologist who reviewed the capabilities agreed by the experts in software development. This led to the roles-capability table (Table IV) proposed in this paper. An example of the justification 


\begin{tabular}{|c|}
\hline Capabilities Demanded by Project Management Processes Roles \\
\hline $\begin{array}{l}\text { The roles involved in the Project Management Processes are: planner (Project Start-Up, Planning and Estimation Process), } \\
\text { controller (Project Monitoring and Control Process), quality engineer (Software Quality Management Process) and role } \\
\text { assigner (Assignation of People to Roles Process). These roles establish the project structure and assure the right level of } \\
\text { project management throughout the whole software life cycle. Their activities involve start up, planning, resource } \\
\text { estimation, monitoring, control, quality management and role specification. }\end{array}$ \\
\hline $\begin{array}{l}\text { To manage the software life cycle and estimate resources, the people who play these roles have to locate and coordinate } \\
\text { important data and recognise significant information. Therefore, their analytical capability needs to be high. A person } \\
\text { without the capability to analyse problems would find it difficult to find solutions to possible problems and to select a } \\
\text { suitable project management structure. }\end{array}$ \\
\hline $\begin{array}{l}\text { These are the people who really decide which path will be taken during the development of the software life cycle, which } \\
\text { means that they should have a high decision-making capability. They have to make decisions quickly, be committed to and } \\
\text { accept responsibility for their decisions. If they are not capable of making or accepting responsibility for their decisions, } \\
\text { problems will arise because they will have to look for authorisation and for someone to take the responsibility. This will } \\
\text { slow down the project, and they will require constant support for their decisions. }\end{array}$ \\
\hline $\begin{array}{l}\text { The level of independence of this group of workers has to be high enough for them to be able to do their job without having } \\
\text { to ask for authorisation, although their teamwork possibilities would be held back if they were too independent. The } \\
\text { required level the capability of independence for this set of roles is medium. Additionally, these people should have the } \\
\text { capability of self-organisation, because they should be able to organise themselves effectively to be able to coordinate and } \\
\text { organise the project management and quality plan and other people's work. }\end{array}$ \\
\hline $\begin{array}{l}\text { Stress tolerance should be sufficient to assure that they do not succumb to regular adversities and opposition. A high level is } \\
\text { required for the Project Start-Up, Planning and Estimation Processes and Project Monitoring and Control Processes, because } \\
\text { it is key factor in the type of work the planner and controller perform, respectively. }\end{array}$ \\
\hline $\begin{array}{l}\text { The innovation or creativity capability required of the four Project Management Processes roles has to be sufficient for them } \\
\text { to be able to find satisfactory solutions to any incidents, but their work is not characterised by a high level of innovation, as } \\
\text { their job will mostly involve coordination and planning, the development of new creative projects being left to other roles. } \\
\text { The process engineer involved in the Organisational Processes will generally propose these projects. }\end{array}$ \\
\hline $\begin{array}{l}\text { The controller should have the capability to foresee and suitably manage risks, estimating their impact to prevent a project } \\
\text { development breakdown. Therefore, high risk management and judgement capabilities are required for this profile, as they } \\
\text { are for the planner with respect to resource estimation for the software project. These estimates should be based on realistic } \\
\text { judgements. Additionally, the capability of negotiating the possible solutions to either each identified and defined risk or for } \\
\text { each particular reprogramming with the senior management and the work team members is also important for the roles of } \\
\text { planner and controller. }\end{array}$ \\
\hline $\begin{array}{l}\text { The planner, controller, quality engineer and role assigner should have medium levels of environmental orientation, because } \\
\text { they need to be sensitive to the different aspects that influence work. As these roles are responsible for project and people } \\
\text { administration, they have to be able to grasp possible or necessary developments in their activity that improve project } \\
\text { management and implementation. }\end{array}$ \\
\hline $\begin{array}{l}\text { As they develop and manage a project requested by a customer, these roles also need to be sensitive to and adapt to the } \\
\text { needs raised by customers and the members of the team, although their job does not directly depend on this capability. } \\
\text { Therefore, they require only a medium level of empathy. }\end{array}$ \\
\hline $\begin{array}{l}\text { Even if only one person embodies project management, this individual needs to have a high teamwork capability, as it is this } \\
\text { person who has to bring the project to the people who will effectively develop it. Therefore, all four roles have to be capable } \\
\text { of actively participating in the achievement of a common goal and be capable of adapting to other people's proposals to } \\
\text { assure that the project goes ahead. }\end{array}$ \\
\hline $\begin{array}{l}\text { As these roles are responsible for planning and management and have also to be capable of specifying the people who will } \\
\text { perform a given role and control the activities to be carried out by each role in the other subprocesses, they need to be } \\
\text { capable of evaluating the performance level of their co-workers, although co-worker evaluation is not actually their job. } \\
\text { Additionally, their leadership capability needs to be high, because the people who perform these roles have to direct their } \\
\text { co-workers towards the achievement of the objectives set out in the project. Defective leadership can impede the } \\
\text { achievement of objectives and increase the planned execution times, because the planned and organised actions are carried } \\
\text { out without the right direction. Establishing order and assuring that the project goes ahead are the very grounds of success } \\
\text { for these processes. Therefore, the capability of planning and organisation is essential for the four Project Managemgty } \\
\text { Processes. }\end{array}$ \\
\hline
\end{tabular}

Figure 2. Justification of the capabilities demanded by project management roles. 
of the capabilities or skills that are required to perform the roles involved in the Project Management Processes is detailed in Figure 2. The justification of the capabilities that are required to properly perform all the other roles considered is detailed in [4].

\section{DETERMINING PEOPLE'S CAPABILITIES}

The Evaluation of People's Capabilities Procedure focuses on how to determine the capabilities of the people involved in software processes. The stages and products are shown in Figure 3.

Identification of Personality Factors develops the Personality Factors Model, which contains the list of behaviours indicative of the personality of each member involved in the process, obtained by means of the 16 PF-5 test. This model will be used as the input for the following stage, Determination of People's Capabilities, where the personality factors are organized and structured in the Preliminary People Model, which will contain the capabilities and behavioural competencies of the people under consideration. The table of correspondence described in Section 5 is used for these structuring purposes. Finally, the People Model is the input for Validation of the People Model, where the capabilities of the person are verified by means of a focused interview. This structured interview is a projective test involving a series of questions designed to provoke flashbacks. The goal of the interview is to precisely and thoroughly test the capabilities of the person to later assign or reassign the person to a given role.

So, the output of the Evaluation of People's Capabilities Procedure is formed mainly by two models (Figure 3): the Personality Factor Model and the People Model. The Personality Factor Model provides a graphic profile of the 16 primary personality factors and the five global dimensions of the 16 PF- 5 test. The questionnaire of this test has been processed using special-purpose software (TEA System 2000), which can be used to correct and later analyse the responses given by each person evaluated. Additionally, this document includes an analytical assessment report for each test factor separately, along with possible strengths and weaknesses of the most representative factors of each person. The People Model coherently integrates the above analytical assessments and presents people's capabilities, alongside the demand level determined by means of the table of correspondence. Additionally, this document involves a synthetic assessment of the personality characteristics and skills of the person. Finally, the Validated People Model is equivalent to the People Model, except that it includes a report on the validation carried out.

It should be explained that this procedure is not performed for each project. The idea is as follows: (a) the organization should have a database containing personnel capabilities; (b) this database should be reviewed every two years to check for individual personality variations; and (c) this information should be used by project managers when they need to assign people to roles.

\section{ASSIGNING PEOPLE TO ROLES}

The Assignation of People to Roles Procedure can be used to assign people to perform roles, that is, to perform activities, according to the capabilities of the people and the demands of the role. To achieve its objective, this procedure involves a profile structuring process, composed of four 


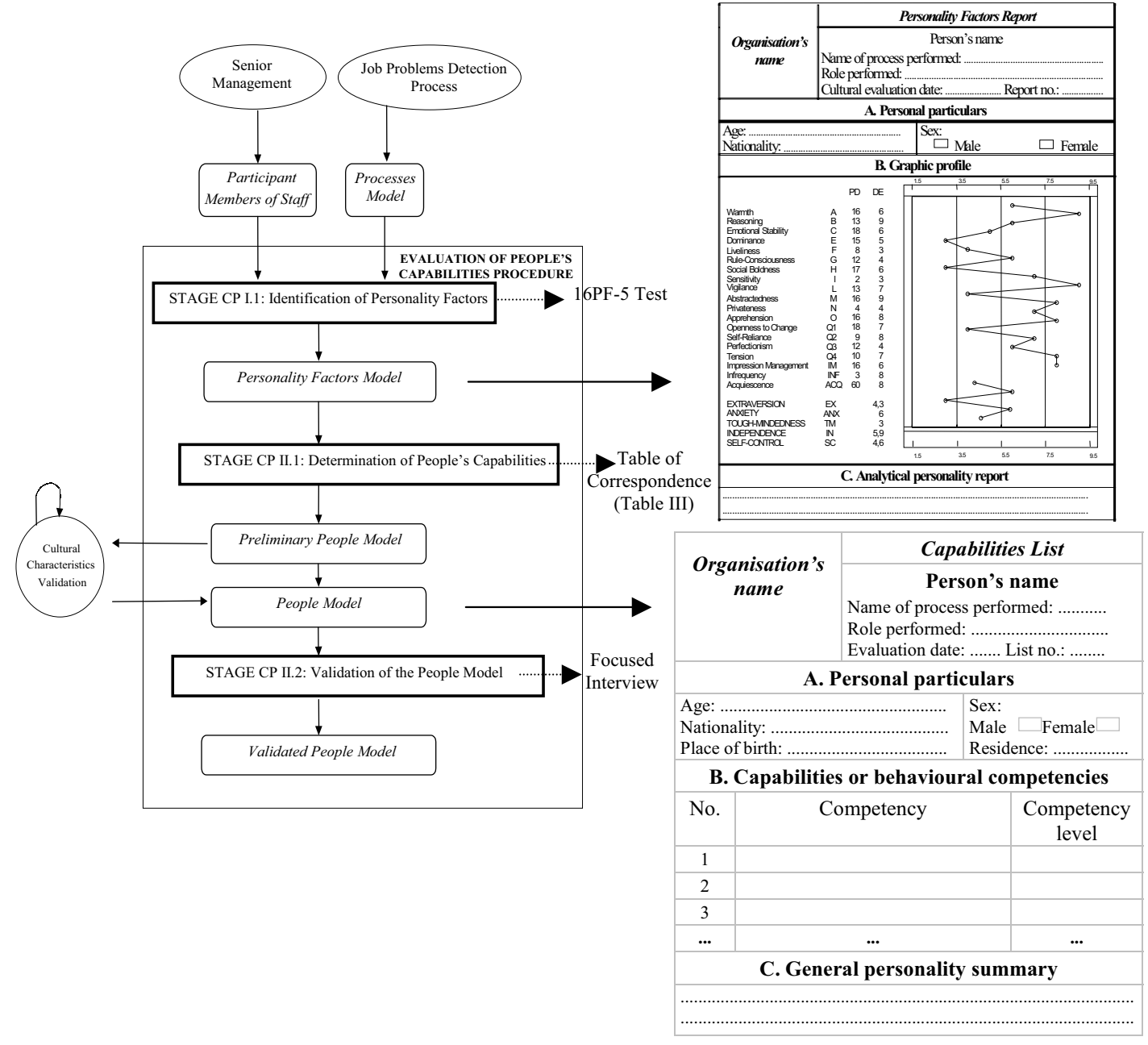

Figure 3. Stages and products of the evaluation of people's capabilities procedure.

activities: (a) comparison, (b) evaluation, (c) monitoring and consolidation, and (d) documentation. These activities, their tasks and associated input and output documents are shown in Figure 4.

The personal-profile/role-profile comparison activity analyses each personal profile against each role profile, looking for the closest match between the personal and role profiles. The Personality Factors Model generated in the Evaluation of People's Capabilities Procedure and the Capabilities per Role Profile (Table IV) are used in this activity. On the basis of these two inputs, we calculate the matches per person and role, that is, for each role, we establish the proportion between the number of individual 


\begin{tabular}{|c|c|c|c|}
\hline ACTIVITY 1 & $\begin{array}{c}\text { Compare personal profile \& role } \\
\text { profile }\end{array}$ & ACTIVITY 4 & File records \\
\hline \multicolumn{2}{|c|}{$\begin{array}{l}\text { Personality Factors Model } \\
\text { Capabilities per Role Profile Table } \\
\end{array}$} & \multirow{2}{*}{\multicolumn{2}{|c|}{$\begin{array}{l}\text { Task 4.1. Identify documents } \\
\text { Task 4.2. Classify documents } \\
\text { Task 4.3. File documents }\end{array}$}} \\
\hline \multicolumn{2}{|c|}{ Task 1.1. Calculate person/role match } & & \\
\hline \multicolumn{2}{|c|}{ Person/Subprocess/Roles Match Table } & \multicolumn{2}{|c|}{ Process Documentation } \\
\hline ACTIVITY 2 & Evaluate results & ACTIVITY 3 & $\begin{array}{l}\text { Monitor and consolidate } \\
\text { performance }\end{array}$ \\
\hline \multicolumn{2}{|c|}{$\begin{array}{l}\text { 2.1. If match }>=50 \%=>\text { person } \rightarrow \text { role } \\
\text { 2.2. If } 30 \%<=\text { match }<50 \%=>\text { person } \rightarrow>\text { role } \\
\text { 2.3. If match }<30 \%=>\text { person } \rightarrow>\text { training } \\
\text { 2.4. Distribution rules } \\
\text { 2.5. Training rules }\end{array}$} & \multicolumn{2}{|c|}{$\begin{array}{l}\text { Task 3.1. Assess performance } \\
\text { Task 3.2. Report deviations } \\
\text { Task 3.3. Right deviations }\end{array}$} \\
\hline \multicolumn{2}{|c|}{$\begin{array}{l}\text { Subprocess/Role/People Table } \\
\text { Subprocess/Role/People/Status Table }\end{array}$} & \multicolumn{2}{|c|}{ Historical Performance Report } \\
\hline
\end{tabular}

Figure 4. Assignation of people to roles procedure.

personality factors that coincide with the personality factors demanded by the role and the total number of factors demanded by the role. Thus, the output of this activity is the Person-Subprocess-Roles Match Table. This table is the input for the evaluate results activity, where we decide whether or not a person is assigned to a role, considering the following rules of assignation.

Note that the discipline of psychology deals with people, which means that we have to use probability rather than static percentages of coincidence (agreement). Accordingly, we aim to predict with the greatest possible probability the behaviour of a person faced with a given role and depending on the responses given by this person to the $16 \mathrm{PF}-5$ personality factor questionnaire.

If the match between the person and the role is greater or equal to $50 \%$, then the person is assigned to the role for respective participation in the project. If there were a similar match with two roles, the person would be assigned to one of the two depending on a higher number of personality factors classified at the high level. If the match between the personal profile and the role profile is lower than $50 \%$ and greater or equal to $30 \%$, the likelihood of a good match between the person and the role is much lower, which means that the only thing to do is to look for a role whose profile is better matched to that of the person. The person would then be assigned to the role in question but will also participate in training programmes to then be assigned to a role with a match greater or equal to $50 \%$.

Otherwise, if the match is less than $30 \%$, the person will be directly sent on training programmes and will then be assigned to the range between $30 \%$ and $50 \%$, participate in the respective role and continue training until the person has a probability of over $50 \%$ of matching a software process role.

Apart from these rules of assignation and training, we have defined distribution rules. For example, in a particular project, where there is an absence of people with the better matches to the roles demanded by the project in question, the percentages of all the people considered are compared for the roles 
involved and the people with the highest percentage and better matched synthetic reports to the role profile are selected. Thus, we get the Subprocess-Role-People Table and the Subprocess-Role-PeopleStatus Table, where status can be participation or training.

It should be explained that the metric of considering a match greater than or equal to $50 \%$ or greater than or equal to $30 \%$ and less than $50 \%$ between the personal profile and the role profile has been determined and validated in this research by means of judges agreement, using the experts meeting technique and consultation of experts in the field of labour psychology and by means of empirical validations in developer organizations.

Both models are inputs to the Monitor and consolidate performance activity, where we assure that the effect of the role-person match is ongoing, assessing whether the personalized assignation has managed to improve current performance, reporting deviations and assuring that this effect does not decrease by applying tested techniques that support and sustain the assignation. The output is the historical performance report, which is appropriately documented in the File records activity and should be taken into account in new role assignations that are performed using this procedure.

\section{PROPOSAL VALIDATION}

We designed an experiment that focuses on the application of the Assignation of People to Roles Procedure to check the people-roles-capabilities relationship and assignation procedure. The main hypothesis to be tested by means of this experiment is that the distribution of roles according to people's capabilities and the capabilities demanded by the role influences software development effectiveness and efficiency. The experiment involves two paired samples, each one containing four software projects carried out by developers at a software developer organization in Argentina. These projects were developed according to the process model activities proposed in [4]. Table V shows the characteristics of the projects considered. The experimentation was run on the project startup, planning and estimation, requirements analysis, design and verification, and validation processes to get the system modelling. In four of the projects selected at random according to statistical principles, the people were assigned to roles according to the team manager's preferences, that is, by experience, which is how it is usually done in software development projects. In the other four projects, the people appointed to perform each of the above-mentioned processes were assigned to the roles of planner, requirements specifier, designer and validator according to the Assignation of People to Roles Procedure described in Section 8. The capabilities of the people involved in each project had previously been defined according to the Evaluation of People's Capabilities Procedure described in Section 7.

The response variables studied in this experiment and their measures by criterion in each project and team are as follows.

- Performance of the person in the role. A process of paired evaluation was carried out on the basis of absolute judgements [10] for the characteristics: leadership, motivation, creativity, initiative, responsibility and commitment for the roles of planner, requirements specifier, designer and validator. The technique of paired evaluation according to absolute judgements employs a questionnaire to assess these characteristics or personality traits quantitatively on a Likert-type scale. Each of these characteristics was scored 1, 2, 3, 4 or 5. 
Table V. Project characterization.

\begin{tabular}{llr}
\hline Project & \multicolumn{1}{c}{ Domain } & $\begin{array}{c}\text { No. adjusted } \\
\text { function points }\end{array}$ \\
\hline Using our proposal & Management of a private dentistry institute. & 522.24 \\
& $\begin{array}{l}\text { Management of quality of life (noise, environmental pollution) } \\
\text { in the city of Santiago de Estero, Argentina. }\end{array}$ & 1205.00 \\
& Administration of UNSE educational self-assessment. & 487.50 \\
& Management of drainage systems. & 130.00 \\
Not using our proposal & Administration and control of UNSE teaching and research. & 1043.10 \\
& Mutual benefit society credit control. & 226.71 \\
& Management of materials and inputs purchase and works & 215.74 \\
& certification for a construction company. & 87.15 \\
& Generation of diets on demand for 3 to 5-year-old children & \\
& with malnutrition in northwestern Argentina. & \\
\hline
\end{tabular}

- Development time. The quotient between the real and estimated time multiplied by 100 was calculated for each team and planning, requirements analysis, design and verification and validation process. Additionally, this same measure was calculated for all four processes as a whole. We should explain that all the projects were estimated by the same person who is experienced in software project estimation.

- Defects in formal inspections. The defects in the formal inspection of the software requirements specification were measured and the percentage of defects over the function points of each project and the percentage of defects over the number of requirements of each project were calculated.

As the projects are different, we use relative measures with respect to development time and defects for the purposes of comparison. As performance is evaluated between pairs from the same team, the measures of the performance characteristics are considered not to be biased by project type. Each person's role performance was actually measured and assessed by people from each team who were blind to the experimental conditions and hypothesis. The Wilcoxon rank sum test statistical technique [32] was used to analyse the data output, as the data source was independent samples that were not normally distributed.

After applying the proposed statistical test for the performance of the person in the role criterion, we got the results that are shown in Table VI, where $m$ is the number of teams applying the treatment (roles assigned according to capabilities) and $n$ is the number of teams without treatment (roles assigned casually). $W$ is the value calculated for the Wilcoxon test used and $p$ the probability of the null hypothesis (the performance of the teams without treatment is the same as the performance of teams where the Assignation of People to Roles Procedure was applied) being rejected when it is actually true. The significance level is $95 \%$. The samples of different sizes are due to data considered to be lacking in some respect, as the samples were originally composed of four teams each. The symbol '*' that accompanies the $W$ value indicates that there is evidence of statistically significant differences 
Table VI. Results for the performance of people in roles criterion.

\begin{tabular}{lllllc}
\hline & & \multicolumn{4}{c}{ Paired evaluation } \\
\cline { 3 - 6 } Role & \multicolumn{1}{c}{ Trait } & $m$ & $n$ & $W$ & $\begin{array}{c}p \text { is less than } \\
\text { or equal to }\end{array}$ \\
\hline \multirow{2}{*}{ Planner } & Leadership & 4 & 4 & $24^{*}$ & 0.050 \\
& Motivation & 4 & 4 & 22.5 & - \\
& Creativity & 4 & 4 & $26^{*}$ & 0.014 \\
& Initiative & 4 & 4 & 23.5 & - \\
Ralidator & Responsibility & 4 & 4 & $26^{*}$ & 0.014 \\
& Commitment & 4 & 4 & $26^{*}$ & 0.014 \\
& Leadership & 4 & 4 & 23 & - \\
Requirements specifier & Motivation & 4 & 4 & 22 & - \\
& Creativity & 4 & 4 & 23 & - \\
& Initiative & 4 & 4 & $24^{*}$ & 0.050 \\
& Responsibility & 4 & 4 & 22 & - \\
& Commitment & 4 & 4 & 23 & - \\
& Leadership & 4 & 3 & $21^{*}$ & 0.029 \\
Motivation & 4 & 3 & 10 & - \\
Creativity & 4 & 3 & $20.5^{*}$ & 0.029 \\
& Initiative & 4 & 3 & 15.5 & - \\
& Responsibility & 4 & 3 & 13.5 & - \\
& Commitment & 4 & 3 & 13 & - \\
& Leadership & 3 & 4 & $17.5^{*}$ & 0.050 \\
& Motivation & 3 & 4 & 13.5 & - \\
& Creativity & 3 & 4 & 16.5 & - \\
& Initiative & 3 & 4 & $17^{*}$ & 0.050 \\
& Responsibility & 3 & 4 & 15 & - \\
& Commitment & 3 & 4 & 16 & - \\
\hline
\end{tabular}

and the probability $p$ is specified in these cases. For example, $p=0.014$ means that null hypothesis (the performance of the teams without treatment is the same as the performance of teams where the Assignation of People to Roles Procedure was applied) is rejected with a confidence level greater than $95 \%$, which is highly significant. The symbol '- ' specifies that there is no evidence of statistically significant differences.

From the results of the performance evaluation of all the roles and the personality traits considered according to the null hypothesis (the performance of the teams without treatment is the same as the performance of teams where the Assignation of People to Roles Procedure was applied), we find that the teams with treatment do manifest statistically significant performance differences in relation to the untreated teams considering the capabilities of leadership for the roles of planner, requirements specifier and designer. The performance evaluation for the trait of creativity is better for the roles of planner and requirements specifier. The evaluation of initiative is better for the roles of validator and designer. The match of people assigned according to the capabilities to the role of planner evidences more effective responsibility and commitment in relation to those assigned casually to the same role. 
Table VII. Results of the development time criterion for each process and the project.

\begin{tabular}{lcccc}
\hline Process & $m$ & $n$ & $W$ & $\begin{array}{c}p \text { is less than } \\
\text { or equal to }\end{array}$ \\
\hline Project start-up, planning and estimation & 4 & 4 & $10.5^{*}$ & 0.029 \\
Verification and validation & 4 & 4 & $10^{*}$ & 0.014 \\
Requirements analysis & 4 & 4 & $10^{*}$ & 0.014 \\
Design & 4 & 4 & $10.5^{*}$ & 0.029 \\
Project & 4 & 4 & $10^{*}$ & 0.014 \\
\hline
\end{tabular}

The results for the development time criterion in each process and for all four processes together (project) are shown in Table VII. The null hypothesis established is that the deviations with respect to the estimated time for the processes are the same in the teams with treatment as in the teams without treatment. The same hypothesis is formulated for the merged processes. The results of Table VII are statistically significant. Accordingly, it can be said that the teams with treatment had a lower deviation in the project development time with respect to the estimated time than the teams without treatment in all four processes. The result with respect to the merged processes is similar.

As regards the defects in formal inspections of the software requirements specification criterion, where we considered number of errors/number of requirements by 100 , we got $w=10(m=4, n=4$, $p \leq 0.014)$ and for the number of errors/adjusted function points by 100 , we got $w=12$ ( $m=4$, $n=4, p \leq 0.050$ ). Considering the null hypothesis that the errors of the groups with treatment have the same percentage of errors as the ones without treatment, our results mean that the groups with treatment can be said to have a lower percentage of errors than those without treatment.

Therefore, the formulated hypothesis that assigning people to roles according to their capabilities and the capabilities demanded by the role improves the software development process is accepted.

\section{CONCLUSIONS}

Our proposal is one of the very few approaches aiming to connect labour psychology and software production. People influence the results of software development and their capabilities should be included as a process model for assigning people to roles according to their capabilities and the capabilities demanded by the role.

In particular, our proposal provides:

- Formalized descriptions of the capabilities of both people and roles and their interactions in the software process.

- Two procedures with defined stages, detailed documents and guidelines for including cultural characteristics, that is, the capabilities of people involved in the software process, and the assignation of roles according to the capabilities of people and the capabilities demanded by each role defined in the process model. These procedures have been evaluated by experimentation.

On the basis of the results obtained in the experiment run, it can be said that the proposed Capabilities-Oriented Software Process Model amounts to an improvement in software process 
modelling. Particularly, the application of the Assignation of People to Roles Procedure can be used to improve development, providing defined guidelines for including the capabilities of the people involved in the software process, making it easier to manage human resources as regards role performance according to their capabilities, as they will effectively and efficiently perform the assigned activities. On the basis of the results of the experiment run, we found that both the deviation in the estimated time and the errors found in the formal inspection of the software requirements specification are lower when the people who perform the roles of planner, requirements specifier, designer and validator are assigned taking into account the set of critical capabilities that the person performing the role should have. Also, from the performance evaluation, the match between the person and the assigned role can be said to be satisfactory, especially for the planner role, and, additionally, the application of the Assignation of People to Roles Procedure improves team performance.

This procedure is especially useful in medium- and large-sized organizations where there is personnel enough to rotate between projects. The People Management Department of these organizations should, as mentioned above, have a database of their technical staff specifying their defined behavioural competencies, and, before assigning people to roles, each project manager should consult this database and apply the proposed Assignation of People to Roles Procedure to match people to roles. This database should be updated every two years according to role performance and participation in the respective training programmes. Even so, problems related to the cost of the associated training programmes, the availability (and willingness) of staff to undergo training, the flexibility of staff (to move from one role to another), how to address existing management/union agreements, and the difficulty in actually using this kind of methods due to individual and group cultural resistance can arise in these organizations.

In small organizations, all staff work on a project and projects are developed sequentially, which means that there is practically no assignation of people to roles for a project, because they all participate in all roles. Nevertheless, it is also useful to conduct a study using the procedures proposed in this paper to analyse the missing behavioural competencies in their teams, that is, what capabilities are not covered and, therefore, require either employee training or the engagement of new people selected purposely to cover these missing behavioural competencies.

These practical implications relate to the need to integrate the proposed Evaluation of People's Capabilities and the Assignation of People to Roles Procedures within the broader context of integrated people management systems. Note that a decision on role assignation takes many other parameters into account, like interpersonal problems between team members and that a person's weaknesses may be compensated for by a close colleague (complementary capability). These questions are now being researched. However, the early evaluations of the assignation of people to roles based on the capabilities approach have been satisfactory and the experiment has demonstrated that the assignation provided by our approach is better than what a team manager would have done with his/her people. Note also that this capability approach is complementary to other existing approaches with traditional strategies used for assigning people to roles, such as approaches focused on domain familiarity and knowledge and know-how. Knowledge is something that we acquire and store intellectually and comprises theoretical knowledge, knowledge on existing things and procedural knowledge. Know-how is related to personal experience and working conditions, and it includes formalized know-how (e.g. the application of working procedures) and empirical know-how (which consists of operational know-how that is hard to structure and to formalize). We are also working on integrating the capabilities model with the experience model to assign people to roles in the software process. 


\section{REFERENCES}

1. Sommerville I, Rodden T. Human, social and organizational influences on the software process. Technical Report CSEG/2/1995, Cooperative Systems Engineering Group, Computing Department, Lancaster University, $1995 ; 1-21$.

2. Humphrey WS. Managing Technical People: Innovation, Teamwork and the Software Process. Addison-Wesley: Reading, MA, 1998.

3. Slomp J, Molleman E. Cross-training policies and team performance. International Journal of Production Research 2002; 40:1193-1219.

4. Acuña ST. Capabilities-oriented integral software process model. PhD Thesis, Universidad Politécnica de Madrid, Madrid, 2002.

5. Hamel G, Prahalad CK. Competing for the Future. Harvard Business School Press: Boston, MA, 1994.

6. Molleman E, Broekhuis M. Sociotechnical systems: Towards an organizational learning approach. Journal of Engineering and Technology Management 2001; 18:271-294.

7. West D. Towards a subjective knowledge elicitation methodology for the development of expert systems. PhD Thesis, University of Portsmouth, Portsmouth, 1991.

8. Hass A. Handbuch Qualifizierungsmodell. Fraunhofer Institut Experimentelles Software Engineering (Fraunhofer-IESE), Internal Report. http://www.iese.fhg.de/ESF-Baukasten/BSK/Quali_Modell [2001]

9. Curtis B, Hefley WE, Miller S. People capability maturity model. Maturity Model CMU/SEI-95-MM-02, Carnegie Mellon University, Software Engineering Institute, 1995

10. Moses JL, Byham WC. Applying the Assessment Center Method. Pergamon: New York, 1987.

11. Avison DE, Wood-Harper AT. Multiview: An Exploration in Information Systems Development. McGraw-Hill: Maidenhead, 1990

12. Checkland PB, Holwell SE. Information, Systems and Information Systems: Making Sense of the Field. Wiley: Chichester, 1998.

13. Stowell FA, West D. Client-Led Design: A Systemic Approach to Information Systems Definition. McGraw-Hill: Maidenhead, 1994

14. Constantine L. Peopleware Papers: The Notes on the Human Side of Software. Prentice-Hall: Englewood Cliffs, NJ, 2001.

15. DeMarco T, Lister T. Peopleware: Productive Projects and Teams (2nd edn). Dorset House: New York, 1999.

16. Cougar JD, Zawacky RA. Motivating and Managing Computer Personnel. Wiley: New York, 1980.

17. Whitaker K. Managing Software Maniacs. Wiley: New York, 1994.

18. Checkland P, Scholes J. Soft Systems Methodology in Action. Wiley: Chichester, 1999.

19. Rodríguez Ulloa RA. Methodology to define Weltanschauungen (M-D-W): An intervention part in a Peruvian problemsituation. Theme II: Management systems. Sistemica 1990; 1(1):63-87.

20. Humphrey WS. Introduction to the personal software process. SEI Series in Software Engineering. Addison-Wesley: Reading, MA, 1997.

21. Humphrey WS. Three dimensions of process improvement. Part III: The team software process. Crosstalk The Journal of Defense Software Engineering 1998; 11(2):14-17.

22. Engels G, Groenewegen L. SOCCA: Specifications of coordinated and cooperative activities. Software Process Modelling and Technology, Finkelstein A, Kramer J, Nuseibeh B (eds.). Research Studies Press: Taunton, Somerset, 1995; 71-102.

23. Min S-Y, Bae D-H. MAM nets: A Petri-net based approach to software process modeling, analysis and management. Proceedings of the 9th International Conference on Software Engineering and Knowledge Engineering, Chang S-K (ed.). Knowledge Systems Institute: Skokie, IL, 1997; 78-86.

24. Fuggetta A. Software process: A roadmap. The Future of Software Engineering, Finkelstein A (ed.). ACM Press: New York, 2000; 27-34.

25. Abdel-Hamid TK, Madnick SE. Software Project Dynamics: An Integrated Approach. Prentice-Hall: Englewood Cliffs, NJ, 1991.

26. Finkelstein A, Kramer J, Nuseibeh B. Software Process Modelling and Technology. Research Studies Press: Taunton, Somerset, 1994.

27. Jacobson I, Booch G, Rumbaugh J. The Unified Software Development Process. Addison-Wesley: Reading, MA, 1999.

28. Boam R, Sparrow P. Designing and Achieving Competency: A Competency-Based Approach to Developing People and Organization. McGraw-Hill: Maidenhead, 1992.

29. Harzallah M, Vernadat F. IT-based competency modeling and management: From theory to practice in enterprise engineering and operations. Computers in Industry 2002; 48(2):157-179.

30. Russell MT, Karol DL. 16PF Fifth Edition Administrator's Manual. Institute for Personality and Ability Testing: Champaign, IL, 1994.

31. Cattell RB, Cattell AK, Cattell HEP. Sixteen Personality Factor Questionnaire (5th edn). Institute for Personality and Ability Testing: Champaign, IL, 1993.

32. Juristo N, Moreno AM. Basics of Software Engineering Experimentation. Kluwer Academic: Boston, MA, 2001. 